\title{
MODEL HYBRID NONLINEAR REGRESSION LOGISTIC (NLR) -DOUBLE EXPONENSIAL SMOOTHING (DES) DAN PENERAPANNYA PADA JUMLAH KASUS KUMULATIF COVID-19 DI INDONESIA DAN BELANDA
}

\author{
Raditya Novidianto ${ }^{1}$ \\ ${ }^{1}$ Jurusan Statistika, Fakultas Sains dan Analitika Data, Institut Teknologi Sepuluh Nopember
}

e-mail: radit@bps.go.id

\begin{abstract}
Abstrak
Hubungan perekonomian Indonesia dan Belanda merupakan hubungan dagang yang sangat erat namun dengan adanya Penyebaran COVID-19 mengganggu berjalannya perekonomian kedua negara tersebut. Sehingga perlunya penjelasan mengenai kondisi COVID-19 untuk menaikkan sentimen pasar perekonomian yang lesu. Berdasarkan hal tersebut digunakan model Hybrid dan non-hybrid untuk meramalkan kondisi penyebaran wabah dan membandingkannya melalui nilai MAPE. Model hybrid nonlinear regression logistic-double exponensial pada jumlah kumulatif COVID-19 tidak cocok digunakan pada kasus COVID-19 Belanda namun cocok digunakan pada jumlah kasus kumulatif COVID-19 di Indonesia. Model hybrid nonlinear regression logisticDouble exponensial merupakan salah satu cara agar mengoptimalkan MAPE khususnya pada data training. Berdasarkan model nonlienar regression logistic bahwa puncak terjadinya wabah Covid19 di Belanda diperkirakan pada 22 November 2020 dan model hybrid nonlinear regression logistic-Double exponensial meramalkan puncak terjadi Covid-19 di Indonesia pada tanggal 28 November 2020. Rata-rata Penurunan kasus setelah terjadinya puncak gelombang Belanda sekitar 2,83 persen dan Indonesia 1,62 persen, oleh karena itu penurunan di Indonesia diprediksi lebih cepat namun Belanda akan mencapai puncak gelombang daripada Indonesia.

Kata Kunci: Covid 19; Forecasting; Nonlinear Regression Logistic; Double Exponential Smoothing
\end{abstract}

\footnotetext{
Abstract

The economic relationship between Indonesia and the Netherlands is a good trade relationship, but the spread of COVID-19 disrupts the two countries' economies. Both countries need to have an explanation regarding the condition of COVID-19 to raise economic market sentiment. Based on this, Hybrid and non-hybrid models are used to predict the dispersion conditions and compare them through the MAPE value. The double-exponential nonlinear logistic regression hybrid model on the cumulative number of COVID-19 is not suitable for use in the Netherlands COVID-19 cases but is suitable for use in the cumulative number of COVID-19 cases Indonesia. The hybrid nonlinear regression logistic-double exponential model is one way to optimize MAPE, especially in training data. Based on the hybrid non-client regression logistic model, the peak incidence of Covid-19 in the Netherlands is estimated at 22 November 2020, and the hybrid nonlinear regression logistic-Double exponential model predicts that the peak of Covid-19 occurs in Indonesia on 28 November 2020. the Netherlands wave is around 2.83 percent and Indonesia 1.62 percent. Therefore the decline in Indonesia is predicted to be faster, but the Netherlands will reach the peak of the Indonesian news wave.
}

Keywords: Covid 19; Forecasting; Nonlinear Regression Logistic; Double Exponential Smoothing 


\section{PENDAHULUAN}

Penyebaran COVID-19 yang terjadi pasti mengganggu berjalannya perekonomian sebuah negara. Evolusi penyakit dan dampaknya terhadap perekonomian tentunya sangat menyulitkan pembuat kebijakan untuk merumuskan kebijakan ekonomi secara makro. (McKibbin and Fernando 2020) menyatakan dampak dari skenario kebijakan ekonomi makro menunjukkan bahwa wabah yang dikendalikan bisa berdampak signifikan terhadap ekonomi global dalam jangka pendek. Pengendalian wabah dan dampak terhadap pertumbuhan ekonomi pada sebuah negara merupakan kunci kestabilan sebuah negara.

Pertumbuhan ekonomi sangat erat dengan hubungan dagang antar negara. Indonesia sendiri memiliki hubungan dagang ke beberapa negara di dunia salah satunya ASEAN, Uni Eropa dan negeri utama lainnya. (BPS n.d.) Januari-Agustus mencatat kontribusi nilai ekspor non migas terhadap negeri di ASEAN (21,07 persen), Uni Eropa (8.7 persen) dan tujuh Negara Utaman lainnya (52.84 persen), sedangkan kontribusi impor dari negara ASEAN (18,89 persen), Uni Eropa (7.99 persen) dan tujuh Negara Utaman lainnya (58.44 persen). Beberapa negara yang mempunyai hubungan dagang dengan Indonesia salah satunya yang menarik adalah dengan negara Belanda di wilayah Uni Eropa. Belanda memiliki hubungan yang positif bagi Indonesia dalam hal ekpor dan impor barang non-migas yaitu ekspor sebesar 2.05 persen dari nilai impor sebesar 0.66 persen terhadap total. Selain memiliki hubungan secara emosional dengan Belanda, Indonesia juga menjadikan Belanda salah satu 13 negara terbesar perannya terhadap nilai ekspor-impor di tahun 2020 walau nilai Free on Board (FOB) turun jika dibandingkan tahun sebelumnya.

Perbandingan data COVID-19 jumlah kasus terinfeksi COVID-19 pada 3 September 2020 Indonesia sebesar 295.499 dan Belanda sebesar 127.786. Indonesia memiliki jumlah kasus COVID 19 pertama yaitu pada 2 Maret 2020 dan memiliki trend naik hingga saat ini dan belum mengalami penurunan jumlah kasus baru sehingga belum pernah mengalami penurunan secara masif jika dilihat dari grafik pada jumlah kasus baru. Jumlah kasus baru harian terbesar yaitu pada tanggal 26 September 2020 yaitu sebesar 4.823 kasus, kemudian kasus baru kecenderungan ditemukan terus meningkat setiap harinya. Dari data tersebut menunjukkan bahwa Indonesia belum pernah berada di puncak gelombang dari mulai kasus ditemukan hingga saat ini. Belanda memiliki kasus pertama pada tanggal 28 Februari 2020 dan memiliki jumlah kasus pada 3 September 2020 sebesar 127.786 kasus. Berbeda dengan Indonesia, jika dilihat dari data jumlah kasus baru COVID-19 maka didapatkan bahwa jumlah kasus baru di Indonesia belum memiliki gelombang namun Belanda sudah memiliki pengalaman melewati puncak gelombang dan saat ini menuju puncak gelombang kedua dari jumlah kasus baru COVID-19. Belanda memilki puncak pertama pada tanggal 11 April 2020 sebesar 1.335 kasus kemudian mengalami penurunan serta mengalami kenaikan kembali hingga tanggal 24 oktober 2020 jumlah penemuan kasus baru sebesar 9.983 kasus dan belum mengalami penurunan hingga saat ini. Perbedaan lagi antara Indonesia dan Belanda dalam kasus COVID-19 yaitu Indonesia belum memiliki pengalaman dalam menghadapi puncak namun Belanda sudah pernah menghadapi pucak gelombang dan akan menghadapi lagi puncak gelombang.

Berdasarkan latar belakang diatas, penulis tertarik untuk membahas analisis lebih mendalam proses pembentukan model hybrid untuk menjelaskan anomali pada jumlah kasus kumulatif dan jumlah penemuan kasus baru dimana Indonesia belum memiliki puncak gelombang dan Belanda memiliki karakteristik hampir memiliki dua gelombang namun gelombang kedua belum mencapai puncaknya. Model hybrid merupakan kombinasi dari model Nonlinear dan Linear yang mengekspolitasi keunggulan dari masing-masing model sehingga mendapatkan hasil yang memiliki akurasi yang tinggi dalam melakukan peramalan. 
Metode hybrid yang digunakan yaitu model nonlinear regression logistic dan hasil residual dimodelkan dengan metode peramalan double exponensial smoothing. Model nonlinear regression logistic merupakan model nonlinear yang memiliki grafik berbentuk sigmoid dan model double exponensial smoothing merupakan model linear yang digunakan jika datanya mengandung tren dan tidak musiman.

Penelitian mengenai nonlinear regression logistic telah dilakukan oleh (Mohammadi et al. 2021) yang meneliti mengenai karakter dari COVID-19 menggunakan nonlinear regression logistic diperoleh bahwa nonlinear regression logistic mempunyai kemampuan yang tinggi dalam melihat perilaku dari COVID-19, selanjutnya (Nusinovici et al. 2020) yang menyimpulkan bahwa nonlinear regression logistic merupakan model yang sangat bagus dalam melakukan prediksi terhadap resiko dari penyakit kronis. Selanjut penelitian mengenai double exponensial smoothing telah dilakukan oleh (Guleryuz 2021) dan (AJUNU et al. 2020). Kedua penelitian tersebut menyatakan bahwa double exponensial smoothing cukup baik dalam melakukan peramalan.

Oleh karena itu, pada penelitian ini akan dilakukan hybrid nonlinear regression logistic dan double exponensial smoothing dengan tujuan agar bisa menjelaskan dengan asumsi kapan akan terjadi puncak gelombang dan kapan berakhirnya gelombang pada Indeonesia dan Belanda pada gelombang yang di alami saat ini dimana kedua negara tersebut memiliki hubungan yang erat dalam pertumbuhan ekonomi sehingga dapan menciptakan kebijakan lebih lanjut untuk mempesiapkan puncak gelombang. Metode Kebaikan akan didapatkan dari nilai MAPE (Mean Absolute Percent Error) yang akan dibandingkan kedua negara tersebut.

\section{METODE PENELITIAN}

\subsection{Data}

Data yang digunakan dalam penelitian ini data jumlah kasus kumulatif COVID-19 dan jumlah kasus baru di Indonesia dan Belanda dengan melihat dinamika data harian disajikan situs resmi (https://ourworldindata.org/coronavirus-testing). Data jumlah kasus COVID-19 terbagi menjadi dua bagian yaitu Data training Data testing. Data training Indonesia dimulai dari dimulainya kasus pertama tanggal 3 Maret 2020 hingga 3 Oktober 2020, sedangkan data training Belanda dimulai dari kasus pertamanya yaitu tanggal 28 Februari 2020 hingga 3 Oktober 2020. Data testing digunakan angka 21 hari kedepan untuk melihat akurasi angka ramalan yang telah dibuat dari data training yaitu dari tanggal 4 Oktober 2020 hingga 23 Oktober 2020.

\subsection{Nonlinear Regression Logistic Growth Model}

Bentuk dari hubungan regresi nonlinear sebagai berikut (Kutner et al. 2005)

$$
Y_{t}=f\left(X_{t}, \theta\right)+\varepsilon
$$

Sehingga persamaan regresi nonlinear logistic dengan $f\left(X_{t}, \theta\right)$ dapat ditulis sebagai berikut

$$
f\left(X_{t}, \theta\right)=\frac{\theta_{1}+\left(\theta_{2}-\theta_{1}\right)}{\left(1+\operatorname{Exp}\left(\frac{x_{t}-\theta_{3}}{\theta_{4}}\right)\right)}+\varepsilon
$$

Dengan $\theta$ adalah fungsi respon nonlinear dari parameternya. (Kutner et al. 2005) menyatakan Error pada regresi nonlinear diasumsikan untuk mempunyai nilai harapan sebesar nol, ragam yang konstan dan tidak dikorelasikan, sama seperti asumsi error pada model regresi linear. 


\subsection{Double Exponensial Smoothing}

Dasar pemikiran dari Double Eksponential Smoothing dari Brown adalah serupa dengan Double Moving Average karena kedua nilai Single Smoothing dan Double Smoothing ketinggalan dari data yang sebenarnya bilamana terdapat unsur trend. (Makridakis et al. 1999) Perbedaan antara nilai Single Smoothing dan Double Smoothing $\left(\mathrm{S}_{\mathrm{t}}{ }_{\mathrm{t}}-\mathrm{S}{ }_{\mathrm{t}}{ }_{\mathrm{t}}\right)$ dapat ditambahkan dengan nilai Single Smoothing $\left(\mathrm{S}_{\mathrm{t}}{ }_{\mathrm{t}}\right)$ dan disesuaikan untuk trend. Rumus yang pakai dalam implementasi Double Exponential Smoothing dari Brown ditunjukkan di bawah ini.

1. Menentukan nilai smoothing pertama $\left(\mathrm{S}_{\mathrm{t}}{ }_{\mathrm{t}}\right)$

$$
S^{\prime} t=\alpha X t+(1-\alpha) S^{\prime} t-1
$$

2. Mentukan Nilai smoothing kedua $\left(\mathrm{S}_{\mathrm{t}}{ }_{\mathrm{t}}\right)$

$$
S^{\prime \prime} t=\alpha S^{\prime} t+(1-\alpha) S^{\prime} t-1
$$

3. Menentukan Nilai Konstanta (at)

$$
a t=2 S^{\prime} t+S^{\prime \prime} t
$$

4. Menentukan nilai slope $\left(\mathrm{b}_{\mathrm{t}}\right)$

$$
b_{t}=\frac{\alpha}{1-\alpha}\left(S_{t}^{\prime}-S_{t}^{\prime \prime}\right)
$$

5. Menetukan Nilai Peramalan

$$
F t+m=a t+b t m
$$

Metode double eksponential smoothing linier dari Holt memuluskan nilai trend dengan parameter yang berbeda dari parameter yang digunakan pada pemulusan data yang asli. Adapun rumus yang digunakan dalam metode double exponential smoothing dua parameter dari Holt dapat dilihat pada persamaan berikut (Makridakis et al. 1999)

$$
\begin{gathered}
S_{t}^{\prime}=a X_{t}+(1-\alpha)\left(S_{t-1}^{\prime}+b_{t-1}\right) \\
b_{t}=\gamma\left(S_{t}^{\prime}-S_{t-1}^{\prime}\right)+(1-\gamma) b_{t-1} \\
F_{t+m}=S_{t}^{\prime}+b_{t} m
\end{gathered}
$$

Proses inisialisasi untuk pemulusan eksponensial ganda dari Holt memerlukan dua taksiran, yaitu $S_{t}$ dan $b_{t}$. proses inisialisasi, diawali dengan memilih $S_{1}=X_{1}$ sedangkan untuk taksiran trend didapat dari rumus $b_{1}=X_{2}-X_{1}$. Adapun konstanta pemulusan $\alpha$ dan $\gamma$ dalam metode peramalan double exponential smoothing berperan sebagai faktor pembobotan. Nilai $\alpha$ dan $\gamma$ bernilai dekat dengan satu, ramalan terbaru akan menyertakan penyesuaian yang besar untuk setiap kesalahan yang terjadi pada ramalan sebelumnya. Sebaliknya jika $\alpha$ dan $\gamma$ dekat dengan nol, ramalan terbaru akan sangat mirip dengan nilai yang lama. 


\subsection{Model Hybrid Nonlinear Regression Logistic (NLR)-Doubel Exponensial Smoothing (DES)}

Menurut (Cobourn et al. 2000)Model hybrid nonlinear regression logistic banyak digunakan dalam kegiatan yang menggambarkankan data melalui model bersifat detail. Model dinamakan hybrid karena terdapat dua persamaan yang terpisah sehingga terdapat kriteria peralihan untuk memilah kepada dua persamaan tersebut pada setiap prediksi. Menurut (Chen and Wang 2007) dalam model hybrid ini, data deret waktu diasumsikan terdiri dari komponen nonlinear dan linear secara sistematis ditulis sebagai berikut

$$
Z_{t}=N_{t}+L_{t}
$$

Dengan $\mathrm{Z}_{\mathrm{t}}$ merupakan data deret waktu pada waktu ke- $t, \mathrm{~N}_{\mathrm{t}}$ merupakan komponen nonlinear waktu ke- $t$ dan $L_{t}$ merupakan komponen linear waktu ke-t. tahap pertama dalam membentuk model hybrid nonlinear regression logistic-double exponensial smoothing adalah membentuk komponen nonlinear. Komponen nonlinear dimodelkan dengan menggunakan model nonlinear. Komponen nonlinear dimodelkan dengan menggunakan model regression logistic dengan input data yang digunakan merupakan input data deret waktu (sampel in). hasil estimasi dari model regression logistic selanjutnya disebut sebagai komponen nonlinear. Kemudian residual dari model regression logistic diasumsikan mengandung hubungan linear. Residual dari model komponen nonlinear menggunakan regression logistic dituliskan sebagai

$$
\varepsilon_{t}=Z_{t}-\widehat{N}
$$

Dengan $\varepsilon_{t}$ merupakan residual model regression logistic waktu ke- $t$ dan $\hat{L}_{t}$ merupakan komponen linear waktu ke-t hasil ramalan dari nilai prediksi model regression logistic. Setelah komponen nonlinear terbentuk, langkah selanjutnya adalah membentuk komponen linear. Komponen linear dimodelkan menggunakan model double eksponesial smoothing dengan input data merupakan residual dari model regression logistic. Model double exponensial smoothing dari residual regression logistic

$$
\varepsilon_{t}=\alpha_{t}+\beta_{t} m+r_{t}
$$

Dengan m merupakan jumlah lag berpengaruh dan $r_{t}$ merupakan residual model double exponensial smoothing pada waktu ke-t. selanjutnya $\varepsilon_{\mathrm{t}}$ menjadi komponen linear waktu ke$t$, sehingga model hybrid nonlinear regression logistic - double exponensial smoothing dapat dinyatakan sebagai

$$
\hat{Z}_{t}=\widehat{N}_{t}+\hat{L}_{t}
$$

Dengan $\hat{Z}_{t}$ merupakan model peramalan hybrid nonlinier regression logistic - double exponensial smoothing, $\widehat{N}_{t}$ merupakan komponen nonlinear waktu ke- $t$ hasil ramalan dari model regression logistic dan $\hat{L}_{t}$ komponen linear waktu ke- $t$ hasil peramalan $\hat{\varepsilon}_{t}$ pada persamaan. 


\section{HASIL DAN PEMBAHASAN}

\subsection{Analisis Deskriptif Data Covid-19}

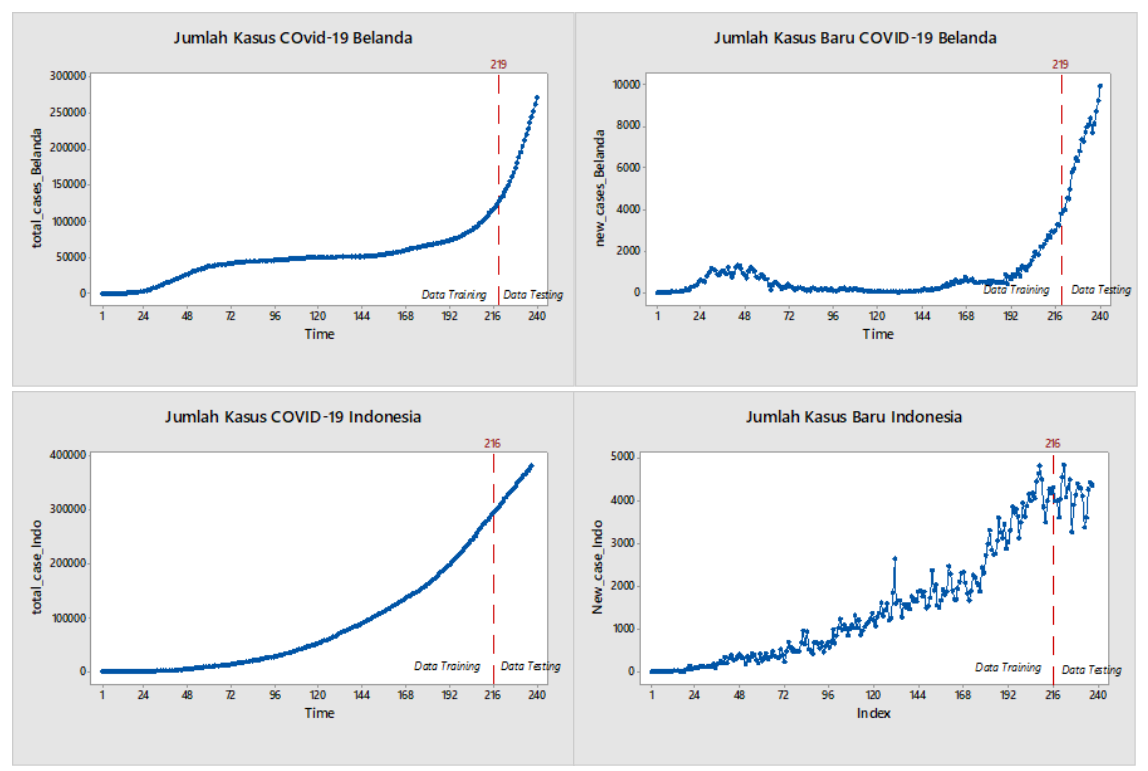

Gambar 1. Grafik Deret Waktu Jumlah kasus dan Jumlah Kasus Baru COVID-19

Gambar 1 menunjukkan bahwa kecenderungan jumlah kasus baru di kedua negara mengelami kenaikkan, namun yang membedakan adalah gelombang terjadi jumlah kasus baru COVID-19. Indonesia belum pernah mengalami puncak gelombang pada jumlah kasus baru COVID-19, namun Belanda sudah pernah memiliki pengalaman berada di puncak gelombang terjadi kasus COVID-19 yaitu pada tanggal 11 April 2020 sebesar 1.335 kasus baru ditemukan setalah itu kasus baru turun dan memulai membentuk gelombang kedua.

\subsection{Nonlinear Regression Logistic}

Tahapan selanjutnya yaitu mencari model terbaik dengan menggunakan metode nonlinear regression logistic. Hal tersebut digunakan untuk membentuk model untuk menjawab kapan kedua negara tersebut dengan asumsi akan mengalami titik puncak dan kapan akan mengalami penurunan. Dalam pemilihan model selain mengasumsikan parameternya agar menjawab pola data maka diperlukan plot pola data yang bisa menjelaskan kapan suatu negara mencapai titik puncak dan turun. Banyak iterasi yang digunakan untuk memperoleh model yang fit untuk dijadikan model dalam peramalan, biasanya model nonlinear regression logistic digunakan untuk prediksi sehingga perlunya ukuran untuk medapatkan model tersebut merupakan model yang baik. Kelebihan model nonliner adalah memilki bentuk yang fleksibel dibandingkan model linear, sehingga perlunya asumsi-asumsi yang diberkan agar model yang dipilih merupakan model yang benar-banar fit. Berikut merupakan simulasi dari mengkombinasi parameter sebagai berikut: 
Tabel 2. Simulasi Parameter Dalam Menentukan Model Terbaik Regression Logistic

\begin{tabular}{lcccccccc}
\hline \multirow{2}{*}{ Skema } & \multicolumn{7}{c}{ Parameter } \\
\cline { 2 - 9 } & $\boldsymbol{\theta}_{\mathbf{1}}$ & $\boldsymbol{\theta}_{\mathbf{2}}$ & $\boldsymbol{\theta}_{\mathbf{3}}$ & $\boldsymbol{\theta}_{\mathbf{4}}$ & $\boldsymbol{\theta}_{\mathbf{5}}$ & $\boldsymbol{\theta}_{\mathbf{6}}$ & $\boldsymbol{\theta}_{\mathbf{7}}$ & $\boldsymbol{\theta}_{\mathbf{8}}$ \\
\hline \multicolumn{7}{c}{ Belanda } \\
\hline Iterasi-1 & 49.973 & 0 & 44 & 1 & 193.678 & 0 & 175 & 1 \\
Iterasi-2 & 46.345 & 0 & 44 & 1 & 600.000 & 0 & 175 & 1 \\
Iterasi-3 & 53.000 & 0 & 44 & 1 & 1.200 .000 & 0 & 175 & 1 \\
\hline \multicolumn{7}{c}{ Indonesia } \\
\hline Iterasi-1 & 600.000 & 0 & 209 & 1 & & & & \\
Iterasi-2 & 1.000 .000 & 0 & 209 & 1 & & & & \\
Iterasi-3 & 1.200 .000 & 0 & 209 & 1 & & & \\
\hline
\end{tabular}

Tabel 2 menjelaskan bahwa seimulasi mendapatkan model terbaik, karena dalam identifikasinya Belanda memilki dua gelombang maka digunakan double logistic untuk dapat menjelaskan gelombang keduanya dan untuk kasus Indonesia hanya single logistic karena dalam kasus COVID-19 baru terdapat satu gelombang dan belum dapat di tentukan puncaknya. Dalam pembentukan model terdapat beberapa iterasi agar mendapatkan model yang fit kemudian model tersebut dilakukan fitting terhadap data training. Kasus COVID19 di Belanda sangat unik karena adanya dua gelombang sehingga pada iterasi-1 menjelaskan skema optimis jika kasus puncak berada pada data terkhir sehingga dianggap terlalu tinggi. Pada iterasi-2 Belanda merupakan skema moderat dimana titik puncak gelombang kedua berada pada total kasus sebanya 600 ribu kemudian pada grafik plot akan cenderung landau karena pada jumlah kasus baru mulai turun. Pada iterasi-3 merupakan skema pesismis dengan asumsi pemerintah belum melakukan inovasi dalam penyebaran COVID-19 sehingga total kasus diasumsikan akan mencapai angka 1,2 juta kasus kemudian selanjutnya grafik jumlah kasus akan melandai karena jumlah kasus baru mulai turun.

Kasus COVID-19 Indonesia hingga saat ini masih belum memilki puncak sehingga data terakhir kecenderungan memiliki jumlah kasus baru yang tinggi. Pada tabel 2 dapat dijelaskan bahwa pada data training jumlah kasus terakhir di Indonesia sebesar 295.499 kasus, pada iterasi-1 yaitu skema optimis jika pada jumlah kasus 600 ribu merupakan jumlah kasus baru tertinggi ditemukan kemudian akan bergerak turun. Kemudian pada iterasi-2 skema moderat menunjukkan bahwa pada jumlah kasus 1 juta merupakan jumlah kasus baru tertinggi yang ditemukan, sedangkan pada iterasi-3 merupakan asumsi jika pada total kasus di Indonesia mencapai 1,2 juta, asumsi tersebut jika Indonesia tidak melakukan inovasi dalam menghambat laju penyebaran COVID-19. Setelah mendapatkan model terbaik maka dilakukan pemodelan dan salah satu cara melihat model terbaik dengan menggunakan grafik Plot sehingga dapat terlihat dengan jelas mana model yang bisa menjelaskan fenomena di kedua negara tersebut. Pada pembuatan model data yang dipakai adalah data total kumulatif kasus kemudian di difference pada lag-1 untuk dilakukan fitting dengan jumlah kasus baru perhari disetiap negara untuk melihat hasil prediksi dari model yang dihasilkan konvergen atau belum. Setelah dilakukan identifikasi akan ditentukan mana model yang benar-benar fit. 

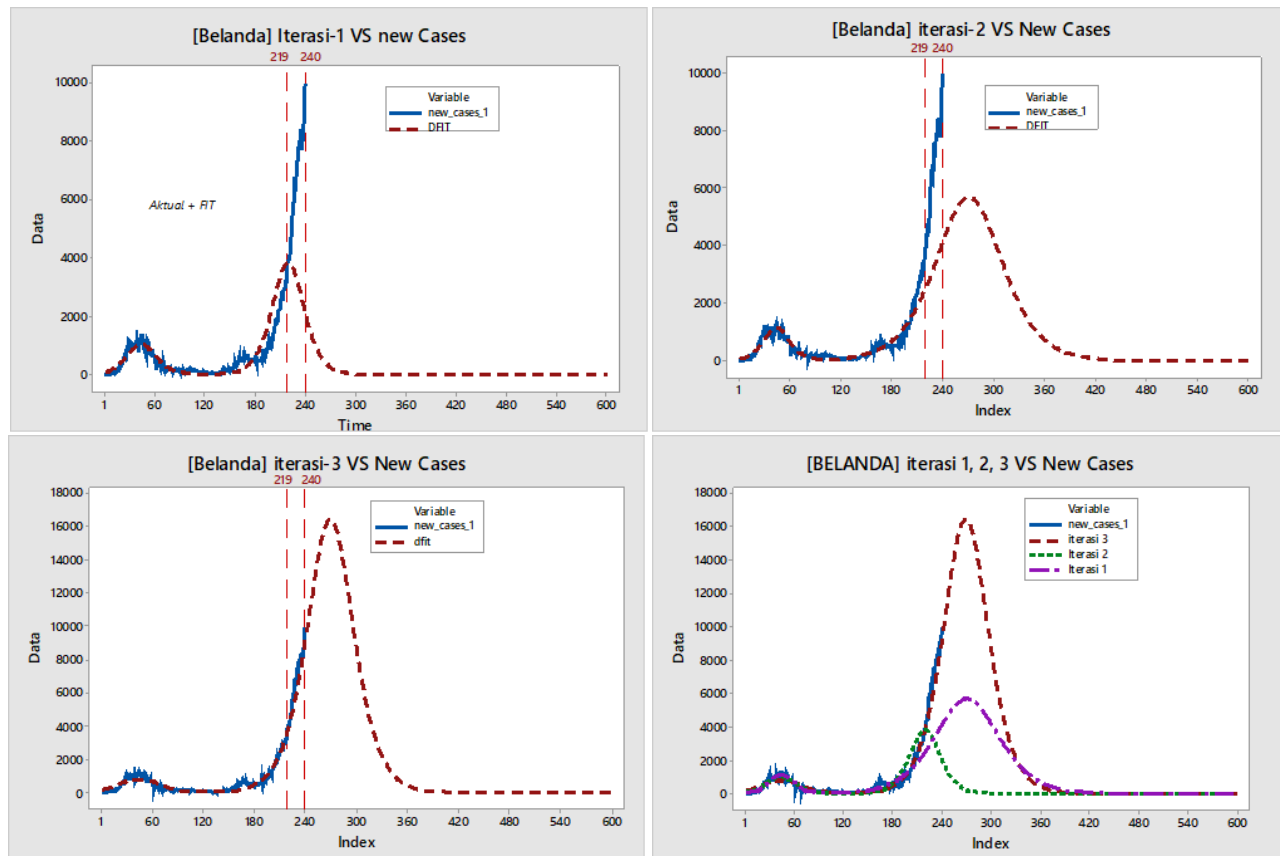

Gambar 2. Time Series Plot Jumlah Kasus Baru Belanda dengan diff Fit mode

Gambar 2 menujukkan time series plot pada setiap model iterasi dengan nilai aktual dimana pada plotnya tidak hanya dengan data training namun dengan data testing juga. Iterasi-1 dan iterasi-2 hanya bisa menjawab model pada data training secara smooth namun pada data testing tidak konvergen. Iterasi-3 mampu menjawab variasi data training dan data testing jika dilakukan fitting pada gambar tersebut terlihat sangat konvergen.
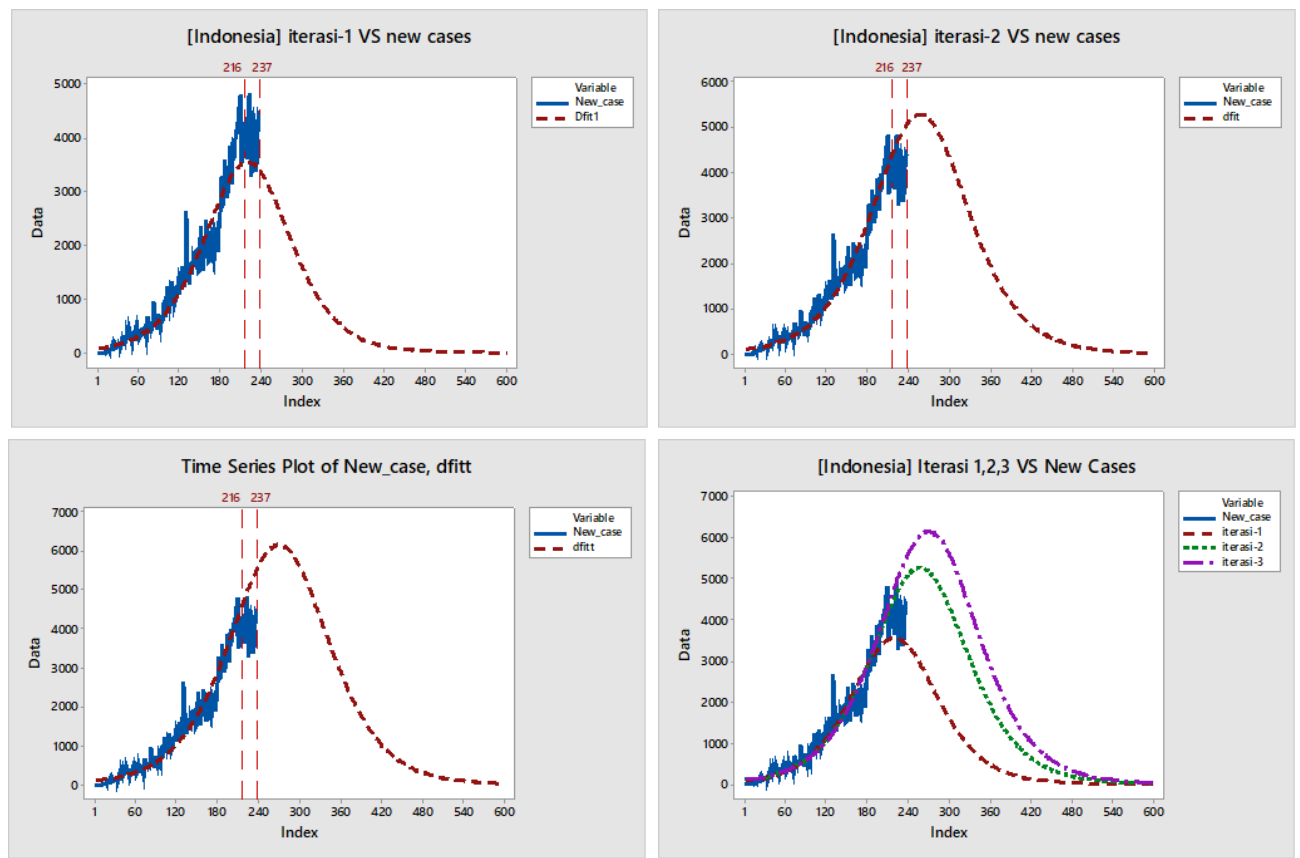

Gambar 3. Time Series Plot Jumlah Kasus Baru Indonesia dengan diff Fit model

Gambar 3 menjelaskan time series plot pada model satu gelombang pada Indonesia yang kecenderungan belum mencapai puncak. Iterasi-1 merupakan model yang optimis ketika Indonesia berada pada titik puncak gelombang pertama, jika diplotkan masih busa menjelaskan data training. Iterasi-2 merupakan puncah berada diatas data training sehingga 
masih bisa untuk menjelaskan data Indonesia secara moderat. Iterasi-3 menjelaskan mengenai kondisi Indonesia jika berada pada titik pesimis yaitu kondisi titik puncak berada di atas data training dan data testing, namun kondisi ini bisa menjelaskan kondisi Indonesia saat ini karena datanya konvergen. Setalah diidentifikasi maka dilakukan forecasting dengan menggunakan data testing dari model nonlinear logistic didapatkan sebagai berikut

Tabel 3. Nilai Mean Error Persentage Error (MAPE) Nonlinear Reg Logistic

\begin{tabular}{lcccccc}
\hline \multirow{2}{*}{ Negara } & \multirow{2}{*}{ training } & \multicolumn{5}{c}{ Forecast data testing } \\
\cline { 3 - 7 } & & $\mathbf{1}$ & $\mathbf{3}$ & $\mathbf{7}$ & $\mathbf{1 4}$ & $\mathbf{2 1}$ \\
\hline Belanda & 34.58 & 0.45 & 0.39 & 0.44 & 1.73 & 2.62 \\
Indonesia & 84.64 & 1.53 & 1.78 & 2.11 & 2.82 & 3.72 \\
\hline
\end{tabular}

Tabel 3. Menunjukkan bahwa nilai Mean Error Persentege Error (MAPE) bahwa jika kita menggunakan nonlinear regression logistic dengan model iterasi-3 pada kedua negara untuk melakukan peramalan maka nilai MAPE pada data training pada kedua negara masih belum bagus, namun jika model tersebut digunakan untuk meramalkan jangka pendek 21 hari kedepan maka MAPE pada data testing pada model cenderung lebih kecil 2,62 persen untuk Belanda dan 3,72 persen untuk Indonesia. Pada tabel 3 juga ditunjukkan bahwa semakin jauh meramal maka semakin besar MAPE yang dihasilkan.

\subsection{Hybrid nonlinear regression logistic - Double Exponensial Smoothing (DES)}

Pada tahap selanjutnya residual dari model nonlinear regression logistic digunakan input data pada model Double Exponensial Smoothing (DES) dengan asumsi bahwa residual memiliki hubungan linear sehingga dimodelkan menggunakan $D E S$. Tujuan digunakannnya model ini yaitu agar data yang masih bersifat belum konvergen maka dengan adanya $D E S$ hasil akurasi peramalan semakin meningkat. Hasil perhitungan dari residual dari model nonlinear regression logistic memeberikan hasil sebagai berikut

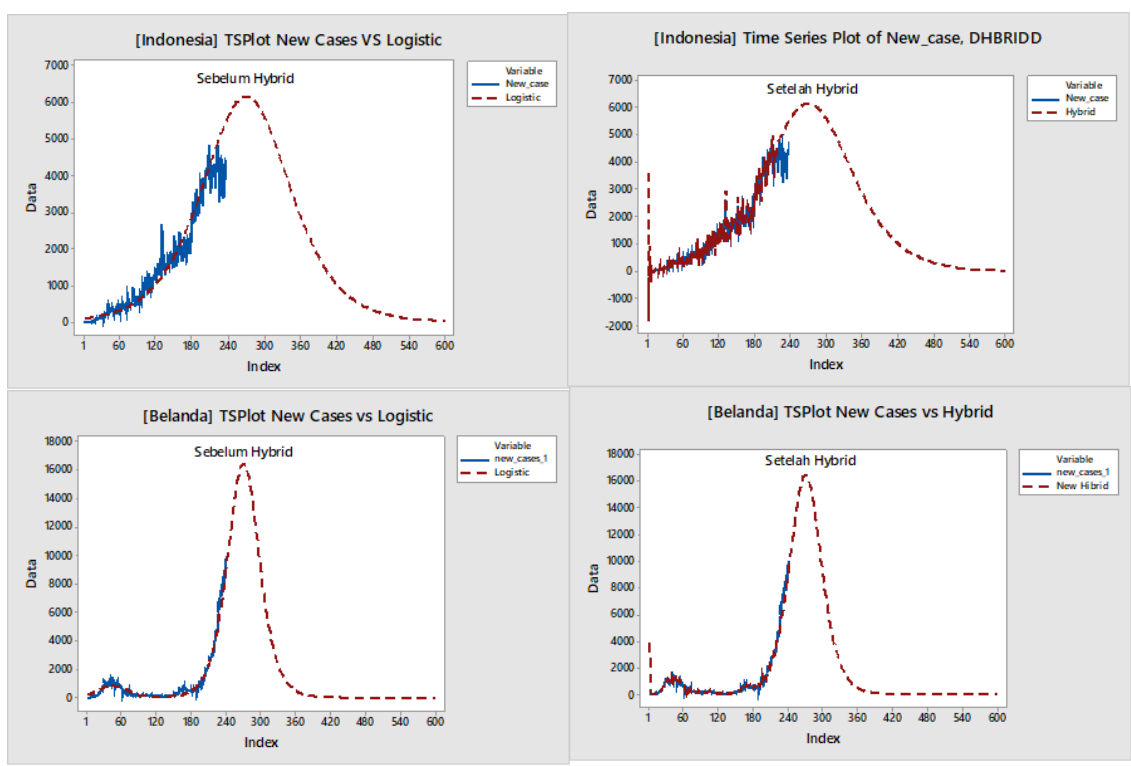

Gambar 4. Time Series Plot Sebelum dan Sesudah model hybrid

Gambar 4 menjelaskan bahwa adanya perubahan pola konvergen dari sebelum hybrid dan sesudah dilakukan hybrid. Belanda sebelum dilakukan hybrid terlihat antara jumlah kasus baru dengan hasil fit yang dihasilkan model masih belum konvergen, namun setelah 
dilakukan hybrid maka terlihat dengan jelas bahwa model tersebut membuat jumlah kasus baru pada Belanda dengan kasus dua gelombang dapat dijelaskan dengan baik. Begitu juga pada jumlah kasus baru yang terdapat di Indonesia untuk kasus satu gelombang model hybrid dapat membuat model menjadi lebih konvergen. Hal tersebut dibuktikan dari nilai MAPE pada model sebagai berikut

Tabel 4. MAPE Model hybrid Nolinear Reg Logistic - Double Exponensial Smoothing

\begin{tabular}{lcccccc}
\hline \multirow{2}{*}{ Metode } & \multirow{2}{*}{ training } & \multicolumn{5}{c}{ forcast data testing } \\
\cline { 3 - 7 } & & $\mathbf{1}$ & $\mathbf{3}$ & $\mathbf{7}$ & $\mathbf{1 4}$ & $\mathbf{2 1}$ \\
\hline Belanda & 1,13 & 0,06 & 0,09 & 0,47 & 1,85 & 2,74 \\
Indonesia & 11,13 & 0,18 & 0,45 & 0,80 & 1,54 & 2,47 \\
\hline
\end{tabular}

Tabel 4 dijelaskan bahwa model yang dihasilkan Belanda dengan menggunakan hybrid nonlinear reglog - DES maka MAPE yang dihasilkan sangat bagus untuk model yaitu 1.13 persen dengan menggunakan data training. Hasil peramalan dapat dilihat bahwa semakin panjang hari yang dilakukan peramalan maka nilai MAPE akan semakin tinggi, untuk peramalan 21 hari nilai MAPE di Belanda sebesar 2,74 persen. Indonesia yang memiliki satu gelombanng jika dilakukan peramalan selama 21 hari memiliki nilai MAPE lebih kecil dari Belanda yaitu sebesar 2,47 persen, dan semakin panjang peramalan yang dilakukan maka semakin besar MAPE yang dihasilkan.

Tabel 5. MAPE Nonlinear Regression Logistic (NLR) dan Model Hybrid NRL-DES

\begin{tabular}{lcccccc}
\hline \multirow{2}{*}{ Metode } & \multirow{6}{*}{ training } & \multicolumn{7}{c}{ testing } \\
\cline { 3 - 7 } & & 1 & 3 & 7 & 14 & 21 \\
\hline \multirow{5}{*}{ B Belanda } & 34,58 & 0,45 & 0,39 & 0,44 & 1,73 & 2,62 \\
$N R L-D E S$ & 1,13 & 0,06 & 0,09 & 0,47 & 1,85 & 2,74 \\
\hline \multicolumn{7}{c}{ Indonesia } \\
$N L R$ & 84,64 & 1,53 & 1,78 & 2,11 & 2,82 & 3,72 \\
$N L R$-DES & 11,13 & 0,18 & 0,45 & 0,80 & 1,54 & 2,47 \\
\hline
\end{tabular}

Perbandingan pada tabel 5 tersebut menjelaskan mengenai bahwa tidak terdapat model yang universal namun setiap model mampu menjelaskan data yang explore. MAPE pada data training Belanda dan Indenesia menjelaskan bahwa model hybrid NRL-DES mampu mereduksi MAPE yang yang besar sehingga lebih minimum. Model pada Belanda untuk hasil forecast 3 hari nilai MAPE lebih rendah menggunakan hybrid NRL-DES, namun ketika meramal pada 7 hari keatas maka nilai MAPE-nya lebih tinggi daripada tidak menggunakan hybrid NRL-DES. Berbeda dengan kasus yang terdapat di Indonesia untuk data testing nilai MAPE lebih rendah hybrid NRL-DES daripada hanya menggunakan nonlinear reg logistic. Sehingga pada intinya model hybrid NRL-DES untuk data training menyebabkan model menjadi konvergen terbukti dari nilai MAPE yang dihasilkan. Dari hasil peramalan untuk Belanda menggunakan nonlinear logistic lebih baik daripada menggunakan hybrid NRL-DES hal tersebut dapat dilihat dari nilai MAPE data training. Indonesia jika dilihat dari nilai MAPE maka model hybrid NRL-DES memberikan hasil akurasi lebih tinggi dalam peramalan dari pada menggunakan nonlinear logistic saja. 


\subsection{Profilisasi dan Interpretasi Hasil Model Terbaik}

Setelah mendapat model yang terbaik maka dilakukan identifikasi untuk melihat kemungkinan terjadinya agar terjadinya kewaspadaan dalam menghadapi titik puncak pada kedua negara, dengan asumsi yang ada maka akan dijelaskan diawal kapan akan terjadi puncak dan kapan berakhirnya. Belanda yang mempunyai pengalaman menghadapi gelombang pertama sekarang menghadapi gelombang kedua sehingga diaharapkan mempunyai penurunannya cukup cepat dibandingkan Indonesia yang belum mencapai puncak gelombang, diharapkan pengalaman Belanda bisa diterapkan di Indonesia saat menghadapi gelombang pertama.
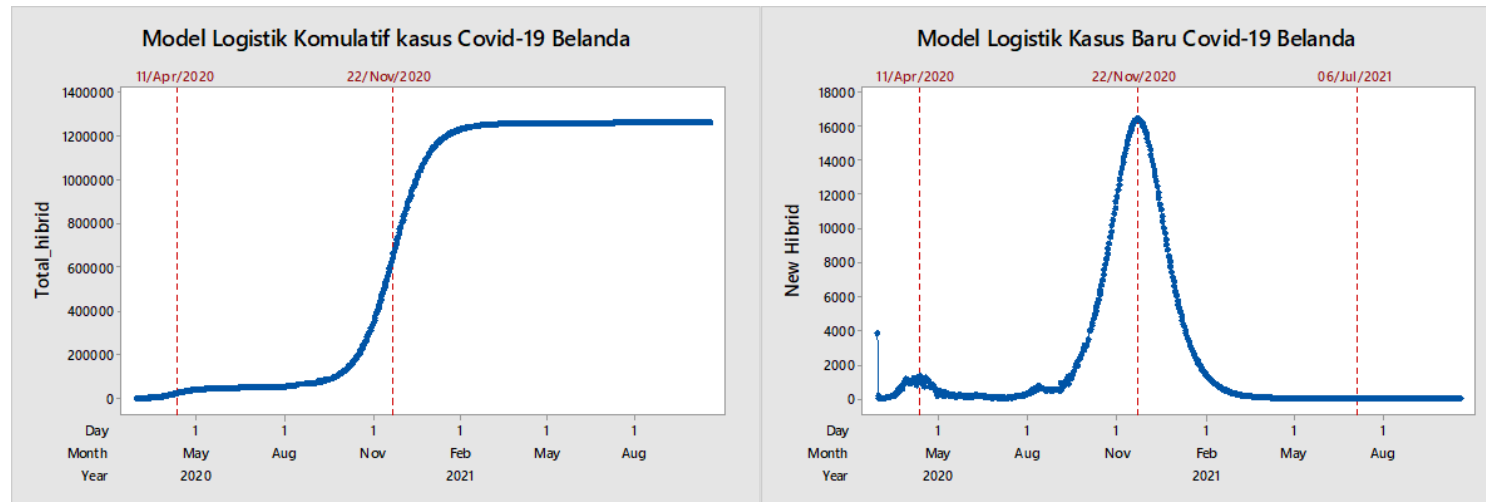

Gambar 5. Model Nonlinear Regression logistic COVID-19 Belanda

Gambar 5 tersebut merupakan model nonlinear regression logistic didapatkan bahwa plot yang menggambarkan kasus di Belanda bahwa di Belanda saat ini terjadi dua gelombang, pada gelombang pertama terjadi pada tanggal 11 April 2020 dengan jumlah kasus baru yang ditemukan yaitu sekitar 1.333 kasus dengan jumlah kumulatif sebesar 23.961 kasus. Pada gelombang pertama dilewati dengan baik oleh Belanda hingga pada Bulan Agustus 2020 terjadi trend kenaikan hingga saat ini. Pada model nonlinear regression logistic tersebut meramalkan puncak gelombang kedua tersebut berada sekitar pada 22 November 2020 dengan total kasus yang baru yang ditemukan pada negara tersebut sekitar 16.455 kasus dengan total kumulatif sebanyak 638.206 kasus. Penurunan jumlah kasus baru setelah titik puncak pada tanggal 22 November 2020 yaitu sebesar 2,83 Persen, dan akan stabil menuju titik nol diperkirakan pada bulan Juni 2021.
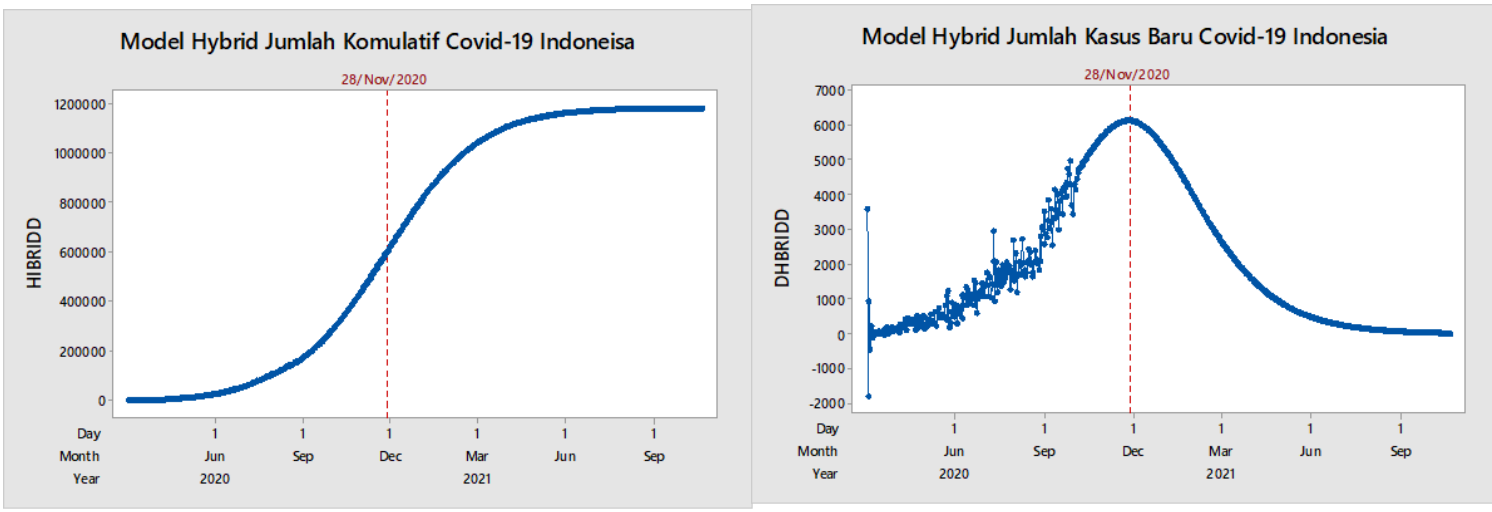

Gambar 6 Model hybrid COVID-19 Indonesia

Gambar 6 menjelaskan mengenai model yang dibuat oleh model hybrid nonlinear regression logistic - double Exponensial smoothing dimana Indonesia saat ini masih berada pada trend naik pada kasus baru yang ditemukan, pada model diperkirakan titik puncak berada pada tanggal 28 November 2020 dengan jumlah kasus 6.115 kasus dengan total kumulatif kasus sebesar 633.869 kasus. Dari titik puncak akan perlahan turun dengan perlahan sebesar 1,62 persen. jika 
dibanding dengan Belanda maka persentase penurunan kasusu lebih cepat Indonesia dibanding Belanda. Titik terakhir berhentinya COVID-19 di Indonesia diperkirakan pada bulan November 2021.

\section{KESIMPULAN}

Berdasarkan hasil dan pembahasan yang telah dilakukan, maka dapat diambil kesimpulan bahwa model peramalan tidak bersifat universal sehingga model hybrid nonlinear regression logistic-Double Exponensial pada jumlah kumulatif COVID-19 tidak cocok digunakan pada kasus jumlah kumulatif COVID-19 Belanda namun cocok di gunakan pada jumlah kasus kumulatif COVID-19 di Indonesia. Model hybrid nonlinear regression logistic-Double exponensial merupakan salah satu cara agar mengoptimalkan MAPE khususnya pada data training. Berdasarkan grafik model NLR bahwa puncak terjadi COVID19 di Belanda diperkirakan berada pada 22 November 2020 dan berdasarkan model hybrid $N L R$-DES di Indonesia pada tanggal 28 November 2020 setelah itu kedua negara mengalami penurunan jumlah kasus baru berdasarkan parameter iterasi-3. Rata-rata persentase penurunan kasus setelah terjadinya puncak gelombang Belanda sekitar 2,83 persen dan Indonesia 1,62 persen, oleh karena itu penurunan di Indonesia diprediksi lebih cepat namun Belanda akan mencapai puncak gelombang terlebih dahulu daripada Indonesia.

\section{DAFTAR PUSTAKA}

Ajunu, Y. I., Achmad, N., And Payu, M. R. F. (2020), "Perbandingan Metode Autoregressive Integrated Moving Average Dan Metode Double Exponential Smoothing Dari Holt Dalam Meramalkan Nilai Impor Di Indonesia," Jambura Journal Of Probability And Statistics, 1. Https://Doi.Org/10.34312/Jjps.V1i1.5393.

Bps (N.D.). "Ekspor-Impor," Available Athttps://Www.Bps.Go.Id/Subject/8/EksporImpor.Html\#Subjekviewtab3.

Chen, K. Y., And Wang, C. H. (2007), “A Hybrid Sarima And Support Vector Machines In Forecasting The Production Values Of The Machinery Industry In Taiwan," Expert Systems With Applications, 32. Https://Doi.Org/10.1016/J.Eswa.2005.11.027.

Cobourn, W. G., Dolcine, L., French, M., And Hubbard, M. C. (2000), “A Comparison Of Nonlinear Regression And Neural Network Models For Ground-Level Ozone Forecasting," Journal Of The Air And Waste Management Association, 50. Https://Doi.Org/10.1080/10473289.2000.10464228.

Guleryuz, D. (2021), "Forecasting Outbreak Of Covid-19 In Turkey; Comparison Of BoxJenkins, Brown's Exponential Smoothing And Long Short-Term Memory Models," Process Safety And Environmental Protection, 149. Https://Doi.Org/10.1016/J.Psep.2021.03.032.

Kutner, M., Nachtsheim, C., Neter, J., And Li, W. (2005), Applied Statistical Linear Models, Mcgraw Hill.

Makridakis, S., Wheelwright C, S., And Mcgee, V. E. (1999), Metode Dan Aplikasi Peramalan, Binarupa Aksara.

Mckibbin, W. J., And Fernando, R. (2020), "The Global Macroeconomic Impacts Of Covid-19: Seven Scenarios,” Ssrn Electronic Journal. Https://Doi.Org/10.2139/Ssrn.3547729.

Mohammadi, F., Pourzamani, H., Karimi, H., Mohammadi, M., Mohammadi, M., Ardalan, N., Khoshravesh, R., Pooresmaeil, H., Shahabi, S., Sabahi, M., Sadat Miryonesi, F., Najafi, M., Yavari, Z., Mohammadi, F., Teiri, H., And Jannati, M. (2021), “Artificial Neural Network And Logistic Regression Modelling To Characterize Covid-19 Infected Patients In Local Areas Of Iran," Biomedical Journal. 
Https://Doi.Org/10.1016/J.Bj.2021.02.006.

Nusinovici, S., Tham, Y. C., Chak Yan, M. Y., Wei Ting, D. S., Li, J., Sabanayagam, C., Wong, T. Y., And Cheng, C. Y. (2020), "Logistic Regression Was As Good As Machine Learning For Predicting Major Chronic Diseases," Journal Of Clinical Epidemiology, 122. Https://Doi.Org/10.1016/J.Jclinepi.2020.03.002. 